\title{
A simulation of transit bus emissions along an urban corridor: Evaluating changes under various service improvement strategies
}

\author{
Ahsan Alam \\ $\mathrm{PhD}$ Candidate \\ Department of Civil Engineering \& Applied Mechanics, \\ Macdonald Engineering Building, 817 Sherbrooke Street West, \\ Montreal, Quebec H3A 2K6, Canada \\ Tel.: 514-473-4594, Fax: 514-398-7361 \\ ahsan.alam2@mail.mcgill.ca

\section{Ehab Diab} \\ $\mathrm{PhD}$ Candidate \\ School of Urban Planning, \\ Macdonald-Harington Building, 817 Sherbrooke Street West, \\ Montreal, Quebec H3A 2K6, Canada \\ Tel.: 514-549-0093, Fax: 514-398-8376 \\ ehab.diab@mail.mcgill.ca
}

\author{
Ahmed M. El-Geneidy \\ Associate Professor \\ School of Urban Planning, \\ Macdonald-Harington Building, 817 Sherbrooke Street West, \\ Montreal, Quebec H3A 2K6, Canada \\ Tel.: 514-398-8741, Fax: 514-398-8376 \\ ahmed.elgeneidy@mcgill.ca \\ Marianne Hatzopoulou (Corresponding author) \\ Assistant Professor \\ Department of Civil Engineering \& Applied Mechanics, \\ Macdonald Engineering Building, 817 Sherbrooke Street West, \\ Montreal, Quebec H3A 2K6, Canada \\ Tel.: 514-398-6935,Fax: 514-398-7361 \\ marianne.hatzopoulou@mcgill.ca
}

\section{Paper published in Transportation Research Part D: Transport and Environment}

For citation please use: Alam, A., Diab, E., El-Geneidy, A. M. \& Hatzopoulou, M. (2014). A simulation of transit bus emissions along an urban corridor: Evaluating changes under various service improvement strategies. Transportation Research Part D: Transport and Environment, 31, 189-198. 


\begin{abstract}
This study investigates the impacts of transit improvement strategies on bus emissions along a busy corridor in Montreal, Canada. The local transit provider, Société de Transport de Montréal, has implemented a number of strategies which include the use of smart cards, limited-stop (express bus) service, and reserved bus lanes along this corridor. Using data collected on-board for instantaneous speeds and stop-level ridership, we estimated bus emissions of greenhouse gases and other pollutants at three levels: road segment, bus-stop, and per passenger. A regression of segment-level emissions against a number of explanatory variables reveals that reserved bus lanes and express bus service reduce emissions significantly. On the other hand, smart card use reduces idling emissions compared to other fare payment methods. Our findings are of most relevance for transit planners who are seeking to implement different strategies to reduce emissions and improve transit performance.
\end{abstract}

Keywords: Transit bus emissions, MOVES, Reserved bus lane, Smart card, Express bus service, Articulated bus. 


\section{INTRODUCTION}

Worldwide concerns for rising greenhouse gas (GHG) emissions in metropolitan areas are often at the forefront of political campaigns and public debates. The transportation sector is one of the largest contributors with about 23\% of GHG emissions (Li et al., 2010). In large metropolitan areas, public transit is considered as an alternative to the private vehicle with a significantly lower carbon footprint. Transit agencies are adopting several improvement strategies to enhance the service and increase its competitiveness. The most widely adopted strategies include implementation of limited-stop (express bus) service, reserved bus lanes, smart cards, queue jumper lanes, and high capacity articulated buses. Several studies have found that express bus service, and reserved bus lanes can decrease bus running times (Kimpel, Strathman, Bertini, Bender, \& Callas, 2005; Surprenant-Legault \& El-Geneidy, 2011; Tétreault \& ElGeneidy, 2010), whereas the introduction of smart cards and articulated buses can potentially increase running times (Diab \& El-Geneidy, 2013; El-Geneidy \& Surprenant-Legault, 2010; ElGeneidy \& Vijayakumar, 2011).

To the best of our knowledge, most of the existing literature has investigated the individual impacts of bus service improvements, and only few studies assessed the combined effects of various strategies on transit bus emissions (Alam \& Hatzopoulou, 2013; Dion, Rakha, \& Zhang, 2004; Hemily \& King, 2008). In this paper we investigate the isolated and combined effects of a range of transit service improvements on the emissions of GHGs and other pollutants along a busy transit corridor in Montreal, Canada. This is done by collecting second-by-second bus speed data and passenger ridership. The resulting segment-level, stop-level, and passengerlevel emissions are analyzed in order to capture the effects of the implemented strategies.

\section{DESCRIPTION OF THE STUDY CORRIDOR}

Boulevard Saint Michel is a busy transit corridor located in the east side of Montreal, Canada. It runs north-south over a 5.8 mile length with Montreal's downtown located on the west side of the corridor (Figure 1). The corridor crosses five boroughs of the City of Montreal and connects two metro stations. Bus service is provided by the local transit provider, Société de Transport de Montréal (STM). Two types of bus service concurrently run along the corridor: regular route 67 (R67) and express route 467 (R467). The majority of the Saint Michel corridor consists of three lanes in each direction with no median separating traffic. Route 67 has an average stop spacing of $241 \mathrm{~m}$ and $255 \mathrm{~m}$ in the southbound (SB) and northbound (NB) directions respectively, whereas the stop spacing for route 467 is $611 \mathrm{~m}$ and $623 \mathrm{~m}$ in the SB and NB directions, respectively.

A slightly shorter sub-segment of the corridor extending between Boulevard Saint Joseph and Rue Fleury is subject to our analysis. It encompasses 28 signalized intersections all of which are equipped with Transit Signal Priority (TSP) system. When a TSP-equipped bus is detected, the signal either provides a green extension or a red truncation (Société de Transport de Montréal, 2011). STM implemented a series of service improvements along the corridor. In April 2008, STM replaced traditional flash passes with a smart card fare collection system called 'OPUS'. In March 2009, STM implemented a limited-stop bus service, also known as express service 467 , running parallel to the regular 67 route. The express service serves only $40 \%$ of the regular bus stops and runs on weekdays (from 6 AM to 7 PM). Later in August 2009, reserved bus lanes were operated during peak periods. The reserved lane becomes effective in the SB direction during the morning peak period (6.30 AM to 9.00 AM) and in the NB direction in the 
afternoon peak (2.30 PM to 6.30 PM). In February 2010, articulated buses were introduced along Route 467. Finally, in September 2011, the STM introduced incrementally articulated buses along Route 67 , offering more space and seating capacity on buses.

In this study the effects of bus service improvements such as smart card, express bus service, and reserved bus lanes are quantified in terms of the resulting bus emissions. Bus emissions are estimated at a segment level where each segment is defined as the journey between the start of the trip and the arrival at the 'Saint Michel' metro station. It was found that the bus ridership at the metro stop changes drastically with a higher number of passengers alighting and boarding at the stop. In the NB direction, two segments are defined spanning 1.75 miles and 2.93 miles whereas in the SB direction, two segments are defined spanning 2.93 and 1.75 miles.

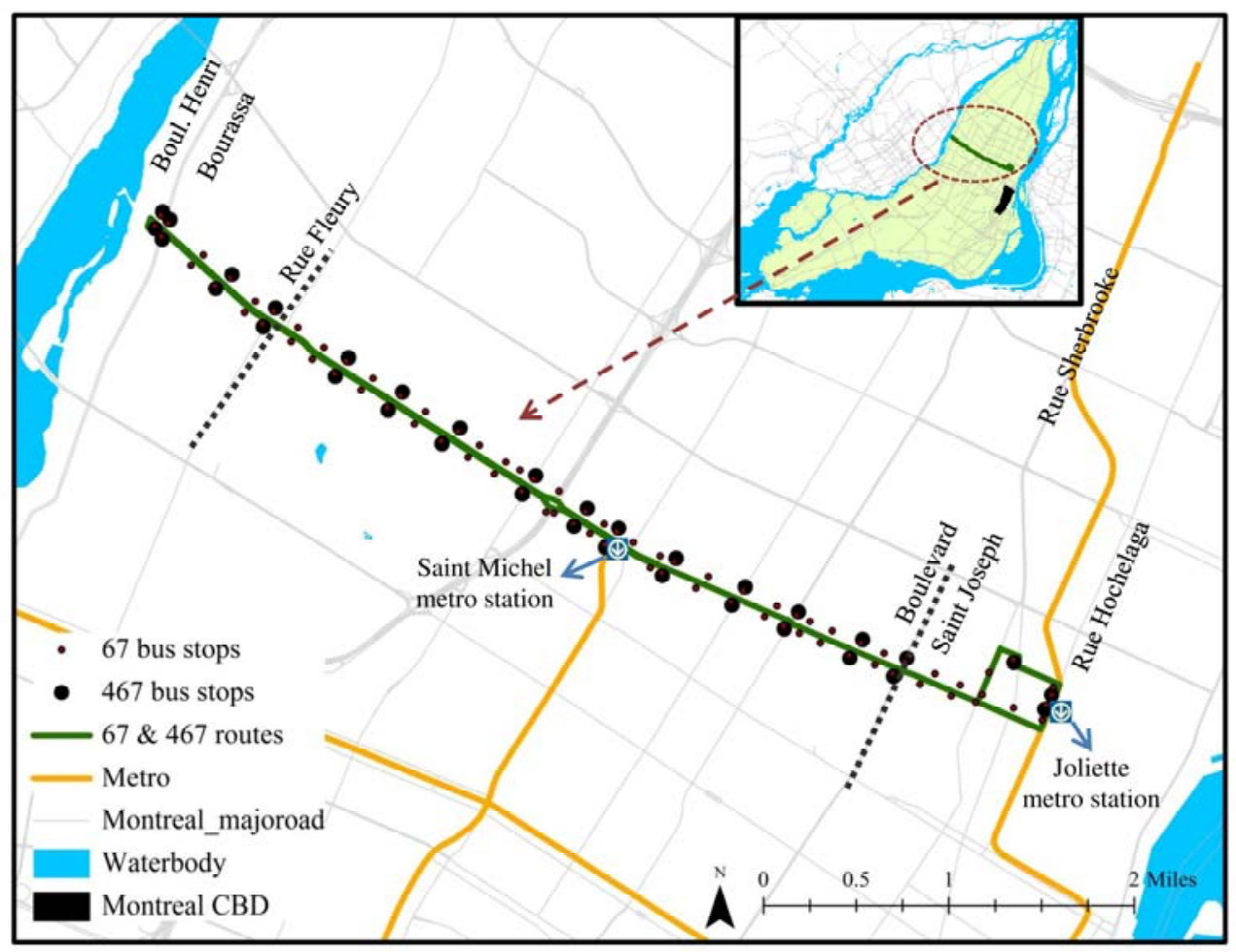

Fig. 1. Saint Michel corridor

\section{METHODOLOGY}

The study methodology is divided into three sections: 1) Data collection (bus speed, passenger ridership, and dwell characteristics), 2) Emission modeling, and 3) Statistical analysis. A comparison of emissions across strategies is performed in order to evaluate the effects of service improvements. A regression of total (including running and dwell) and dwell emissions against a number of operational variables is conducted to unveil the associations between various strategies affecting service and bus exhaust emissions. The overall methodology of the study is presented in Figure 2.

\subsection{Collection of bus data}

A data collection campaign was designed and executed over the span of two weeks in October 2013. Data from a total of 96 trips were collected for both routes (regular and express). 
A trip is defined from the beginning to the end of one route in a single direction (NB and SB). For each route, 24 trips were covered in the morning and afternoon peaks totaling 48 trips, spread equally over the two directions. In this research, we focus on articulated buses emissions only as regular buses are operated occasionally due to STM ongoing plan to shift all buses running on Montreal heavily used corridors to articulated by 2020 (Riga, 2012). Data were collected by research assistants riding the buses with three research assistants present in each bus. Each research assistant was located near to one bus door. The instantaneous speeds of the buses were collected using global positioning system (GPS) devices. Data from two separate GPS devices were collected in each bus for quality control. The allocation of research assistants and GPS units to trips/buses were randomized.

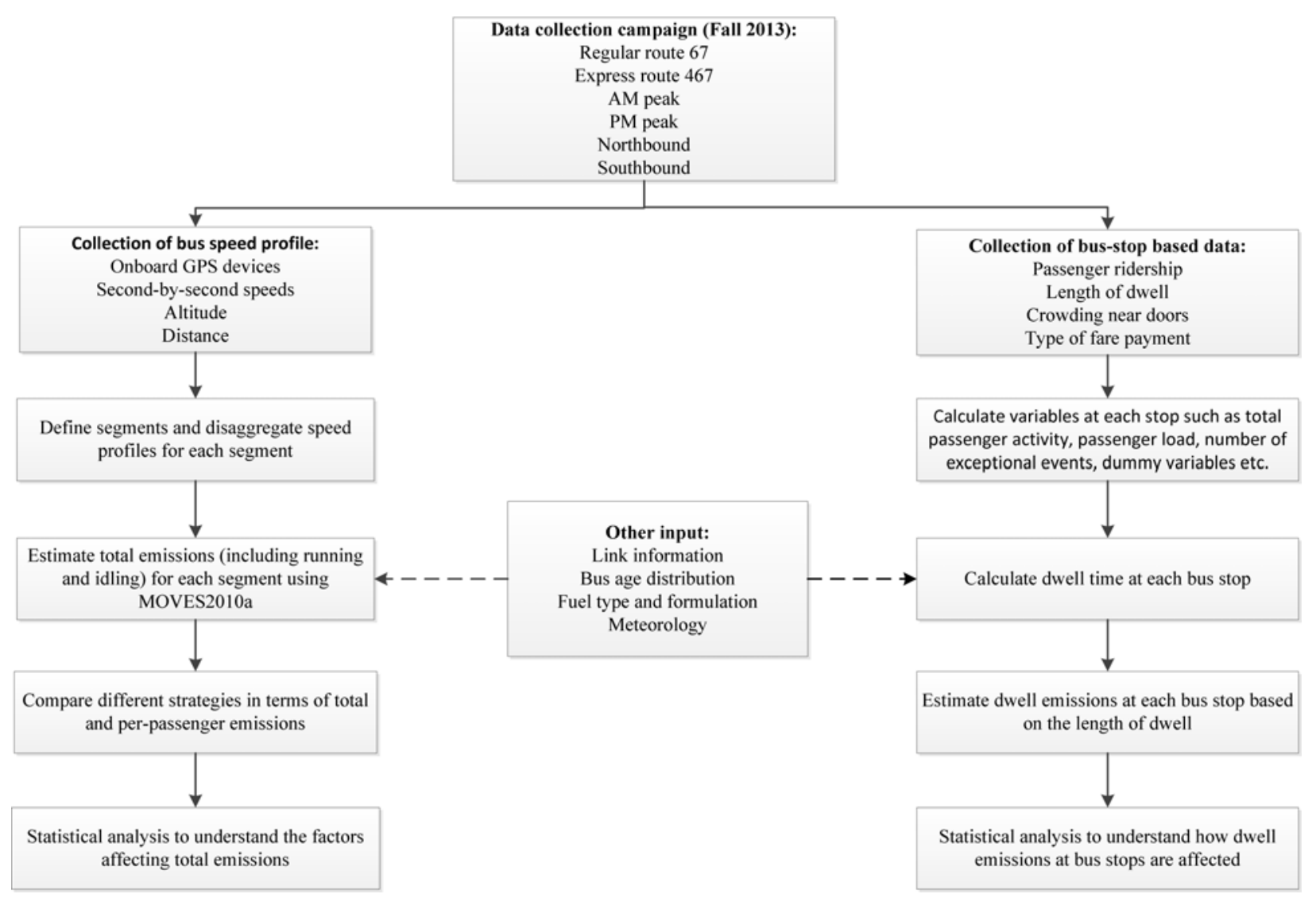

Fig. 2. Overall methodology of the study

Stop level data were collected using a tally sheet and stopwatch. At each bus door, a research assistant recorded the number of individuals boarding and alighting and the idling time at each stop. In addition, the fare payment associated which each boarding was recorded, payment types include: smart card 'OPUS', magnetic swipe, cash, and no fare. The smart card has an electronic chip embedded into the card and the passengers have to attach the card to a chip reader to be validated. The duration for the validation usually varies between 1 to 3 seconds. On the other hand, the magnetic swipe card is a paper-based ticket which has a magnetic strip along one side of the ticket. Passengers have to swipe the card through a reader and this process often varies from 2 to 4 seconds. Finally, cash users have to place the fare (either by cash or coins) into a farebox. The length of this process varies largely from one person to another. The total idling time at each bus stop was recorded from door opening to door closing. This idling time was 
recorded at each door for two stages: (1) the required dwell time for passengers boarding and alighting, and (2) any excess time that was not associated with boarding and alighting defined as exceptional dwell such as a stop due to a red signal or a conversation with a passenger. In addition, the number of individuals standing near the door (defined as crowding) after the bus departure from the stop was also recorded at each door.

A data cleaning process was conducted by removing incomplete trips associated with recording errors such as missing GPS signals. Data cleaning was also conducted at the stop level. Data were excluded if (1) dwell time was reported even though no passenger activity occurred at a bus stop, (2) when recordings were flagged by research assistants as possibly erroneous (e.g. due to GPS malfunction or inability to count passengers), (3) the recorded dwell time was zero even though passenger activity occurred, and (4) if the dwell time at a single stop was recorded as exceeding 200 seconds. Finally, the trip-level second-by-second speed profiles were split into two based on the location of the metro stop. Data for a total of 192 segments (96 trips divided into two) were collected. Following the data cleaning process, a total of 132 segment level and 1,556 stop level observations remained for analysis.

\subsection{Emission modeling}

Emissions generated during bus operations are estimated using MOVES2010a, developed by the United States Environmental Protection Agency (USEPA). It has the ability to estimate emissions at macro, meso, and micro levels. To estimate emissions, the former two levels use the average speed of a vehicle whereas the latter uses instantaneous speeds. In this study bus emissions were estimated using second-by-second speeds collected with the GPS devices. Emissions were estimated for GHGs (in $\mathrm{CO}_{2}$-equivalent), fine particulate matter ( $\mathrm{PM}_{2.5}$ ), carbon monoxide $(\mathrm{CO})$, and nitrogen oxides $\left(\mathrm{NO}_{\mathrm{x}}\right)$ at the (1) segment level (including running and idling) and (2) stop-level (only idling).

To estimate emissions, MOVES requires additional inputs such as link length and grade; fuel type and formulation; vehicle type; vehicle model year; and meteorology including temperature $\left({ }^{\circ} \mathrm{F}\right)$ and relative humidity $(\%)$. The link length for each segment is calculated from Google Map and validated using geographic information systems (GIS) and onboard-GPS data. All current buses are articulated buses and run on Ultra Low Sulfur Diesel (ULSD) with a sulfur content of $15 \mathrm{ppm}$. Meteorological data were input in the form of hourly temperature $\left({ }^{\circ} \mathrm{F}\right)$ and relative humidity (\%). Meteorology data were collected from Environment Canada and it was found to be fairly stable during the duration of the data collection. Therefore average values of $50.3 * \mathrm{~F}$ temperature and $74 \%$ relative humidity were used.

When MOVES estimates emissions, it does not differentiate the type of bus (regular or articulated); it also assumes a constant bus weight of 16.556 tons. However, articulated buses are heavier than regular buses and they require more tractive power to operate the vehicle. In this study, we have explicitly considered the effect of bus weight estimating emissions. Articulated buses operating along the route have an empty weight of 18.86 tons (with a seating capacity of 47 and total capacity of 112). We also consider an average passenger weight of $75 \mathrm{~kg}$. Bus weight (including passenger load) was used to estimate the vehicle specific power (VSP) and operating mode category (opmode). The VSP represents the tractive power exerted by a vehicle to move itself and its passengers. It is a function of instantaneous speed, acceleration, vehicle weight, and road grade as shown in equation (1) (USEPA, 2010). 


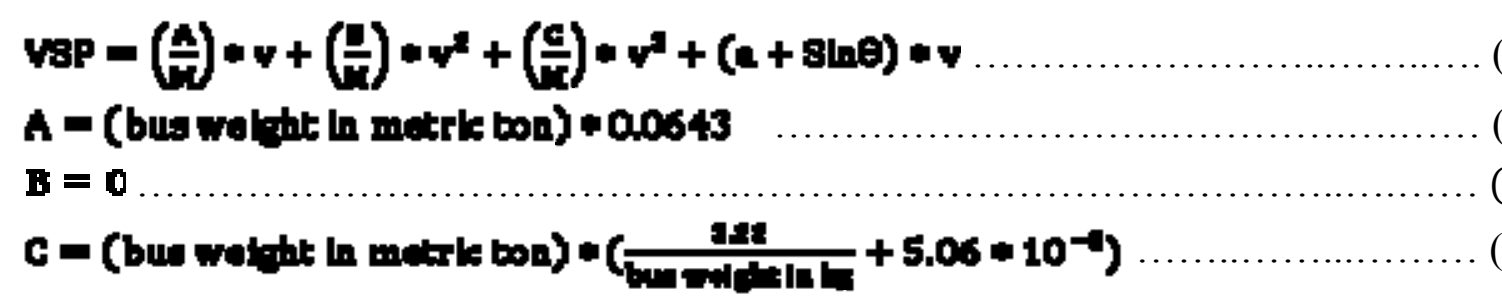

Where $\mathrm{A}, \mathrm{B}$, and $\mathrm{C}$ are the road load coefficients in units of (kiloWatt second)/(meter), (kilowatt second $\left.)^{2}\right) /\left(\right.$ meter $\left.^{2}\right)$, and (kiloWatt second $\left.{ }^{3}\right) /\left(\right.$ meter $\left.^{3}\right)$, respectively. The denominator term, ' $\mathrm{M}$ ', is the fixed mass factor (for heavy vehicle such as transit, $\mathrm{M}=17.1$ tons), ' $\mathrm{g}$ ' is the acceleration due to gravity $\left(9.8\right.$ meter/ second $\left.{ }^{2}\right)$, ' $v$ ' is the vehicle speed in meter/second, ' $a$ ' is the vehicle acceleration in meter/second2, and $\operatorname{Sin} \theta$ is the (fractional) road grade.

The terms, A, B, and C, are weight dependent. As the segments in the study corridor are relatively flat, we considered a grade of zero. Using equation (1), the VSP was calculated for each second during the trip. In MOVES, an opmode is determined by following a combination of speed and VSP for each second. Therefore, based on the VSP and speed, the opmode was determined for every second of the corresponding drive cycle. In the next step, for each segment travel the amount of seconds spent in each opmode was calculated and an opmode distribution was developed. The opmode distribution provides the amount of time that the vehicle has spent under different opmode categories. This opmode distribution was input into MOVES to estimate emissions at a segment level. In MOVES, each opmode has a particular emission rate $(\mathrm{gm} / \mathrm{hr})$ that is dependent on a number of variables such as fuel type, meteorology, and vehicle age.

\subsection{Statistical analysis}

In order to capture the effects of various service improvement strategies and bus attributes on emissions, a linear regression is estimated. The analysis is intended to capture how emissions vary at a segment level as well as at a stop level. The list of variables tested is presented in Table 1 along with the mean and standard deviation of each variable.

\section{RESULTS}

\subsection{Descriptive analysis of onboard data collected}

The data collection effort was conducted for both routes, both peak periods, and both directions. Figure 3 presents the bus travel time for the combinations of direction and time of day. We observe that the NB-pm and SB-am combinations have higher travel time which is inline with morning and afternoon commuting patterns. Reserved lanes are operated for these two combinations of direction and time of day; nevertheless, the average bus speed remains around $7.7 \mathrm{mph}$. We also observe that the SB-pm combination (without reserved lane) has a higher travel time as non-commuters often travel towards the downtown in the afternoon peak period to engage in various activities. This figure also shows that the express bus route R467 has consistently lower travel time. With reserved lanes, the travel time for the express bus decreases by a larger amount (compared to the case without the reserved lane) compared to the effect of the reserved lane on travel time of the regular bus suggesting that the reserved lanes along this corridor are more effective for express buses. 
Table 1 Description of variables tested in the statistical analysis

\begin{tabular}{|c|c|c|c|}
\hline Variable Name & Description & Mean & $\begin{array}{c}\text { Std. } \\
\text { Deviation }\end{array}$ \\
\hline \multicolumn{4}{|c|}{ Segment level total emissions (running + idling) } \\
\hline $\begin{array}{l}\text { GHG Emissions Rate } \\
\text { (g/bus.mile) }\end{array}$ & $\begin{array}{l}\text { Total GHG emissions in grams generated by one bus for travelling one } \\
\text { mile during a segment travel }\end{array}$ & $2,214.46$ & 475.21 \\
\hline $\begin{array}{l}\text { PM2.5 Emissions Rate } \\
\text { (mmg/bus.mile) }\end{array}$ & $\begin{array}{l}\text { Total } \mathrm{PM}_{2.5} \text { emissions in milligrams generated by one bus for travelling } \\
\text { one mile during a segment travel }\end{array}$ & 29.46 & 4.65 \\
\hline $\begin{array}{l}\text { Total Passenger } \\
\text { Activity (PAX) }\end{array}$ & $\begin{array}{l}\text { The total number of passengers boarding and alighting during a segment } \\
\text { travel }\end{array}$ & 97.05 & 50.37 \\
\hline PAX Square & Square of the PAX value during a segment travel & $11,935.59$ & $12,864.18$ \\
\hline R467 & A dummy variable that equals 1 if the trip was made on route 467 & 0.59 & 0.49 \\
\hline Reserved Bus Lane & $\begin{array}{l}\text { Dummy variable which equals } 1 \text { if the observed trip used the reserved bus } \\
\text { lanes. When it is equal to 1, this means the trip was made between } 6: 30 \\
\text { AM and 9:00 AM in the southbound direction or between } 2: 30 \mathrm{PM} \text { and } \\
\text { 6:30 PM in northbound }\end{array}$ & 0.44 & 0.5 \\
\hline Southbound & $\begin{array}{l}\text { Dummy variable which equals } 1 \text { if the trip was made in the southbound } \\
\text { direction }\end{array}$ & 0.57 & 0.5 \\
\hline AM Peak & $\begin{array}{l}\text { A dummy variable which equals } 1 \text { if the trip was made in the morning peak } \\
\text { period (6:30 AM- 9:30 AM) }\end{array}$ & 0.46 & 0.5 \\
\hline PM Peak & $\begin{array}{l}\text { A dummy variable which equals } 1 \text { if the trip was made in the afternoon } \\
\text { peak period ( } 3: 30 \text { PM- } 6: 30 \mathrm{PM})\end{array}$ & 0.54 & 0.5 \\
\hline $\begin{array}{l}\text { Segment Level } \\
\text { Crowding }\end{array}$ & $\begin{array}{l}\text { Total number of passengers standing near the door during the whole } \\
\text { segment }\end{array}$ & 22.35 & 27.42 \\
\hline \multicolumn{4}{|c|}{ Bus stop level idling emissions } \\
\hline $\begin{array}{l}\text { Total Idling GHG } \\
\text { Emissions }\end{array}$ & Total amount of GHG emissions for idling at each bus stop & 117.33 & 110.93 \\
\hline Smart Card User & Number of boarding passengers paying fare by smart card & 4.64 & 6.44 \\
\hline $\begin{array}{l}\text { Magnetic Swipe Card } \\
\text { User }\end{array}$ & Number of boarding passengers paying fare by magnetic swipe card & 0.16 & 0.79 \\
\hline Cash User & Number of boarding passengers paying fare by cash & 0.15 & 0.45 \\
\hline No Fare User & Number of boarding passenger paying no fare & 0.15 & 0.48 \\
\hline Door 1 Alight & Total number of passengers alighting through door 1 & 1.57 & 2.04 \\
\hline Door 2 Alight & Total number of passengers alighting through door 2 & 1.9 & 3.06 \\
\hline Door 3 Alight & Total number of passengers alighting through door 3 & 1.63 & 3.15 \\
\hline $\begin{array}{l}\text { Stop Level PAX } \\
\text { Square }\end{array}$ & $\begin{array}{l}\text { Square term of the PAX value at a bus stop where PAX is calculated as the } \\
\text { sum of total passengers boarding and alighting at a stop }\end{array}$ & 239.68 & 735.04 \\
\hline $\begin{array}{l}\text { Bus Stop Level } \\
\text { Crowding }\end{array}$ & $\begin{array}{l}\text { Total number of passengers standing near the door when the bus arrives at } \\
\text { the stop }\end{array}$ & 2.53 & 4.09 \\
\hline
\end{tabular}


Figure 4 illustrates the average number of onboard passengers. We observe that when reserved lanes are used under congested conditions, more commuters are found on the express bus (R467), presumably because of the faster travel time. On the other hand, when the reserved lane is not in effect, more commuters are found on the regular bus (R67) despite its higher travel time. A possible reason could be that non-commuting passengers prefer regular service because it serves more stops.

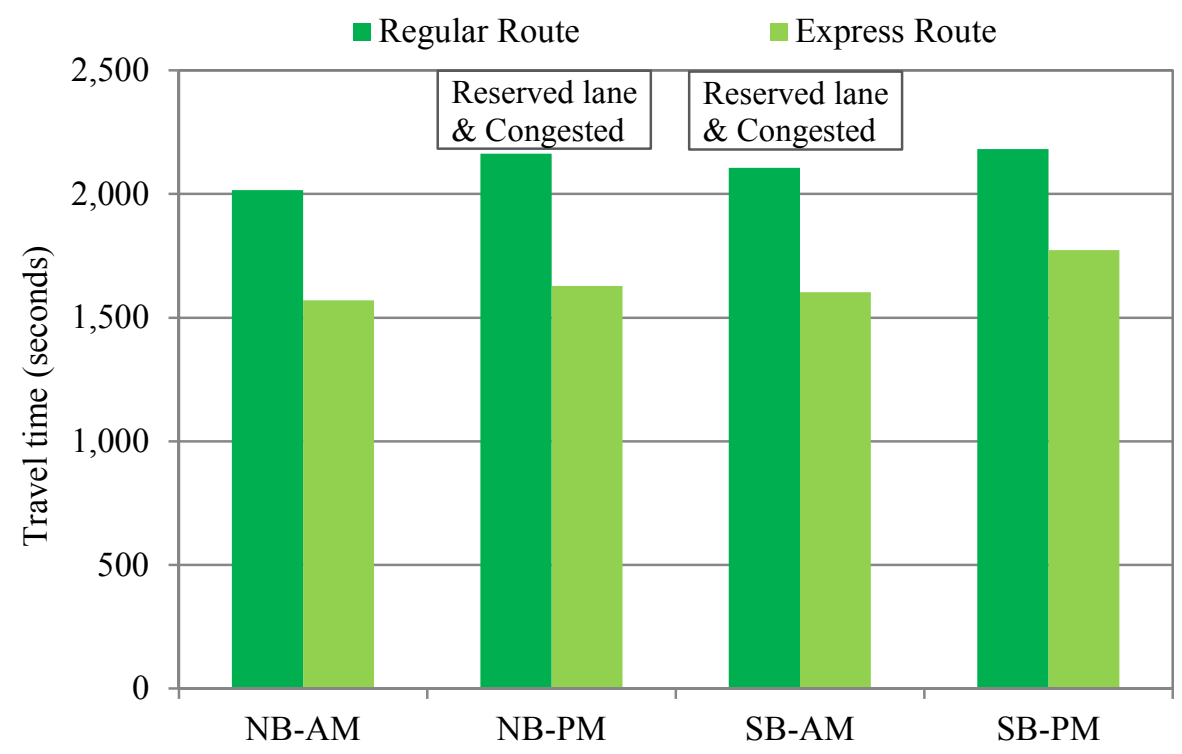

Fig. 3. Travel time along different directions and time periods for regular (R67) and express (R467) buses

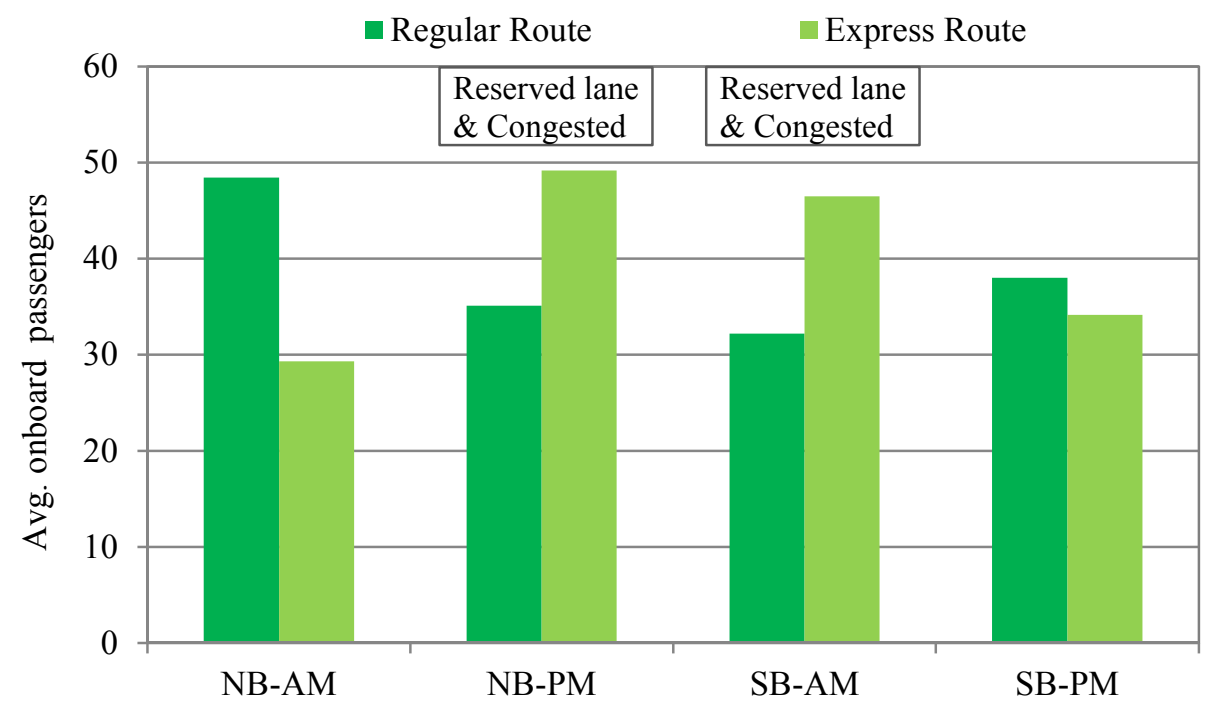

Fig. 4. Average number of onboard passengers along different directions and time periods for regular (R67) and express (R467) buses 


\subsection{Descriptive analysis of estimated emissions}

Total emissions per segment (including running and idling) were estimated for each bus trip. Segment-level emissions were also compared across different combinations of route and reserved lane facility. Figure 5(A) illustrates average segment-level GHG emissions (in $\mathrm{g} /$ bus.mile) while the bus is running and idling. We observe that running emissions are highest when buses operate in regular service without a reserved lane. When buses are operated on the express route and use reserved lanes, running emissions are lowest. In terms of idling emissions, we observe that regular buses without reserved lane generate the highest emissions and express buses without reserved lanes generate the lowest. Also note that even with the same number of onboard passengers at a segment level, regular buses have more idling emissions because of more frequent stops. It is also interesting to see that express buses generate higher idling emissions when reserved lanes are in effect because of the higher passenger ridership during these times. Also note that the benefit of express buses can be potentially increased by decreasing their idling emissions associated with waiting behind a regular bus at a bus stop. Figure 5(B) illustrates the variability in total emissions over the entire dataset. For the regular route, we observe a large variability in trip-level emissions because of the higher number of bus stops. The variability is lowest for express service and reserved lane. This happens because the service improvements not only reduce travel time but presumably also yield a stable, smooth flow having less 'stop and go' events. It is also interesting to see that the changes in travel time (i.e. average speed) do not necessarily translate into linear changes in emissions highlighting the importance of using second-by-second bus speeds in emission estimation (Table 2).

In addition, per passenger GHG emissions were calculated by dividing the total emissions per segment (including running and idling) by the average number of onboard passengers and summarized as an emission rate in g/pass.bus.mile (Figure 6). We observe that per passenger emissions are highest on the regular bus without a reserved lane while the regular bus with reserved lane and express bus without reserved lane come close. The reason for this small difference is attributed to passenger ridership. Even though regular buses without the reserved lane produce higher emissions, they also have the highest ridership which reduces per passenger emissions. On the other hand, for the next two combinations, service improvements (i.e. express bus and reserved lane) reduce total emissions but lower ridership doesn't help reduce per passenger emissions largely. By looking at the spread in per passenger emissions, we observe that there are cases where the bus produces more emissions per passenger than a private auto with a driver and a passenger (assuming $125 \mathrm{~g} /$ passenger.mile for a typical 2011 car with 2 individuals). Finally, express buses in a reserved lane have the lowest per passenger emissions. The variability in emissions is also smaller for express buses on reserved lanes indicating that they have more stable passenger ridership, probably because of high proportion of commuters to downtown.

In addition to GHG, we also estimated emissions for $\mathrm{PM}_{2.5}, \mathrm{CO}$, and $\mathrm{NO}_{\mathrm{x}}$. Figure 7 illustrates the percentage reduction for each pollutant by comparing each bus-lane combination with the emissions of the regular bus without a reserved lane (base case). We observe that the express buses and reserved lanes are also effective at reducing these pollutants. 
(A)

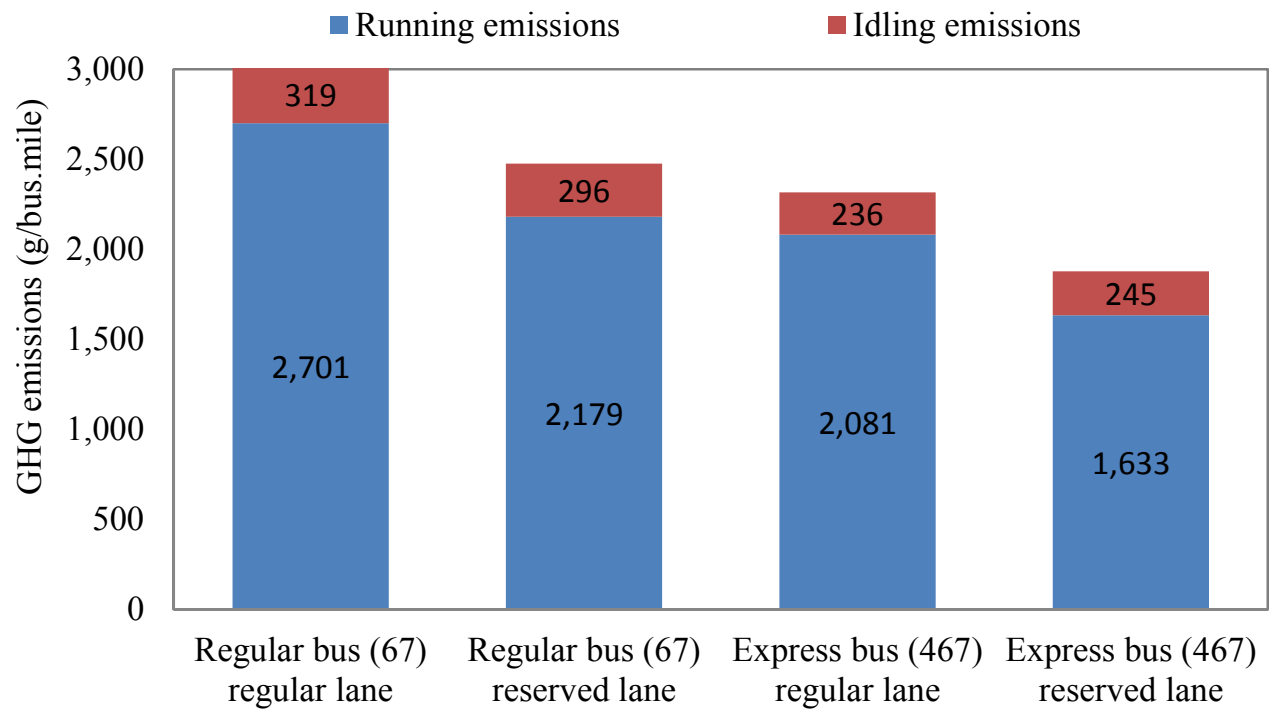

(B)

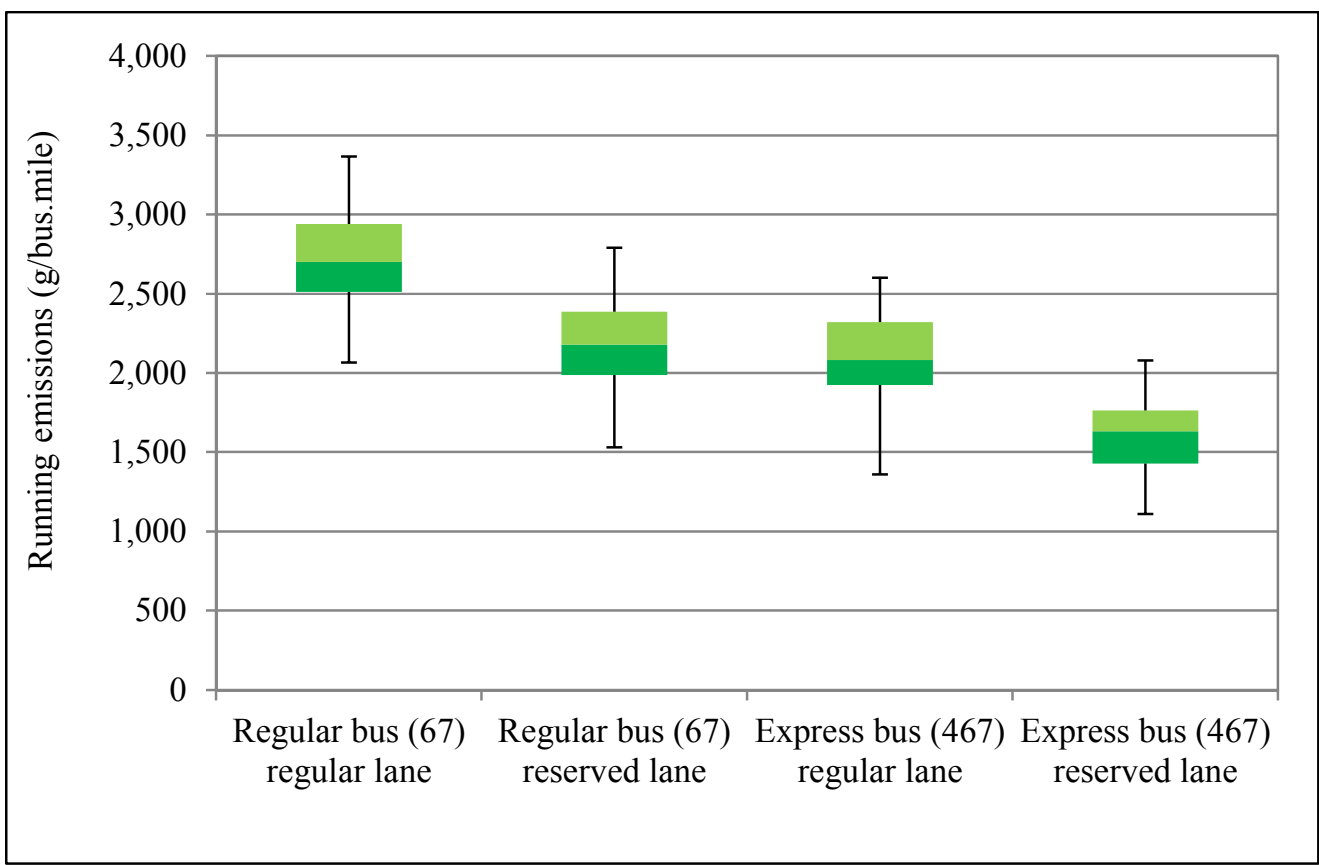

Fig. 5. GHG emissions under different combinations of bus route and lane facility. (A) Mean running and idling GHG emissions under different combinations of bus route and lane facility. (B) Variability in running GHG emissions under different combinations of bus route and lane facility. 
Table 2 Percent reductions in average travel time and average GHG emissions reduction under various service improvements (compared to the case of the regular bus without a reserved lane)

\begin{tabular}{|c|c|c|}
\hline Combinations & $\begin{array}{c}\text { Avg. travel time } \\
\text { reduction (\%) }\end{array}$ & $\begin{array}{c}\text { Avg. GHG emissions } \\
\text { reduction (\%) }\end{array}$ \\
\hline $\begin{array}{c}\text { Regular bus (67) \& } \\
\text { reserved lane }\end{array}$ & 2.13 & 18.01 \\
\hline $\begin{array}{c}\text { Express bus (467) \& } \\
\text { regular lane }\end{array}$ & 20.39 & 23.29 \\
\hline $\begin{array}{c}\text { Express bus (467) \& } \\
\text { reserved lane }\end{array}$ & 23.04 & 37.84 \\
\hline
\end{tabular}

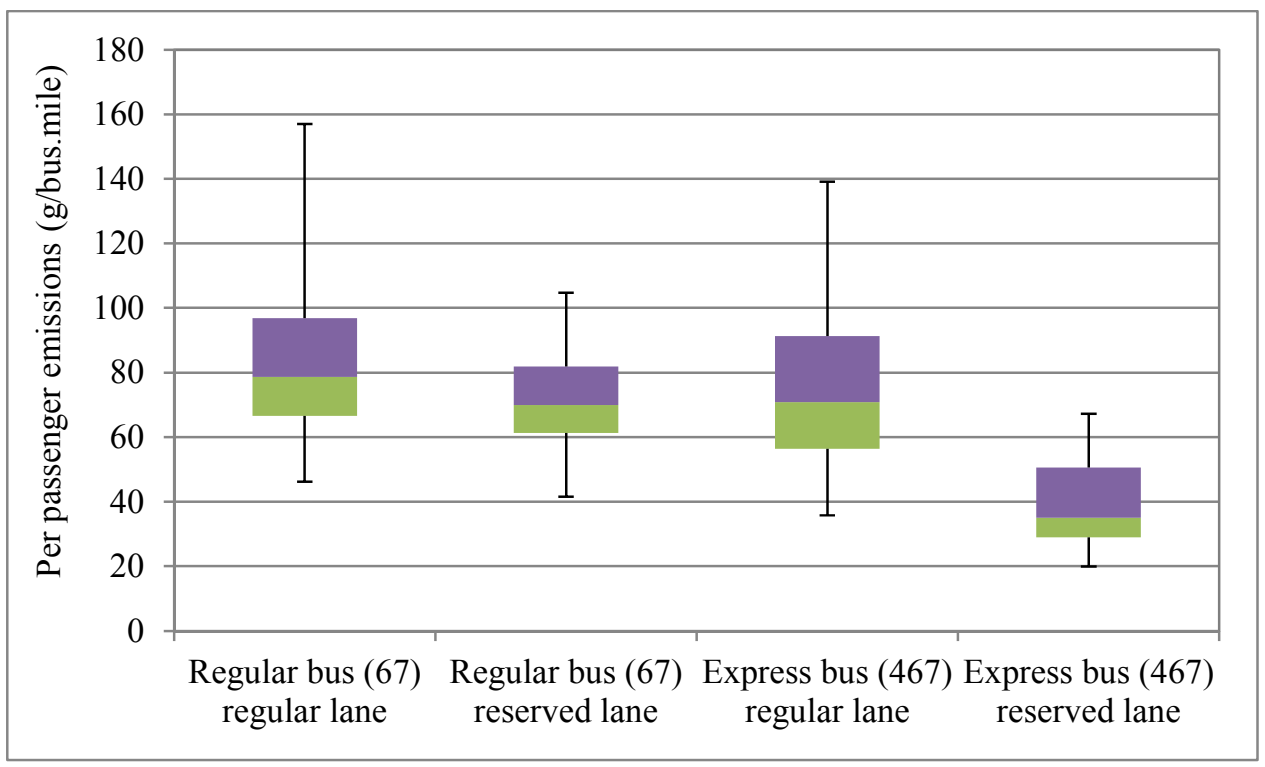

Fig. 6. Per passenger GHG emissions variation under different combinations of bus route and lane facility 


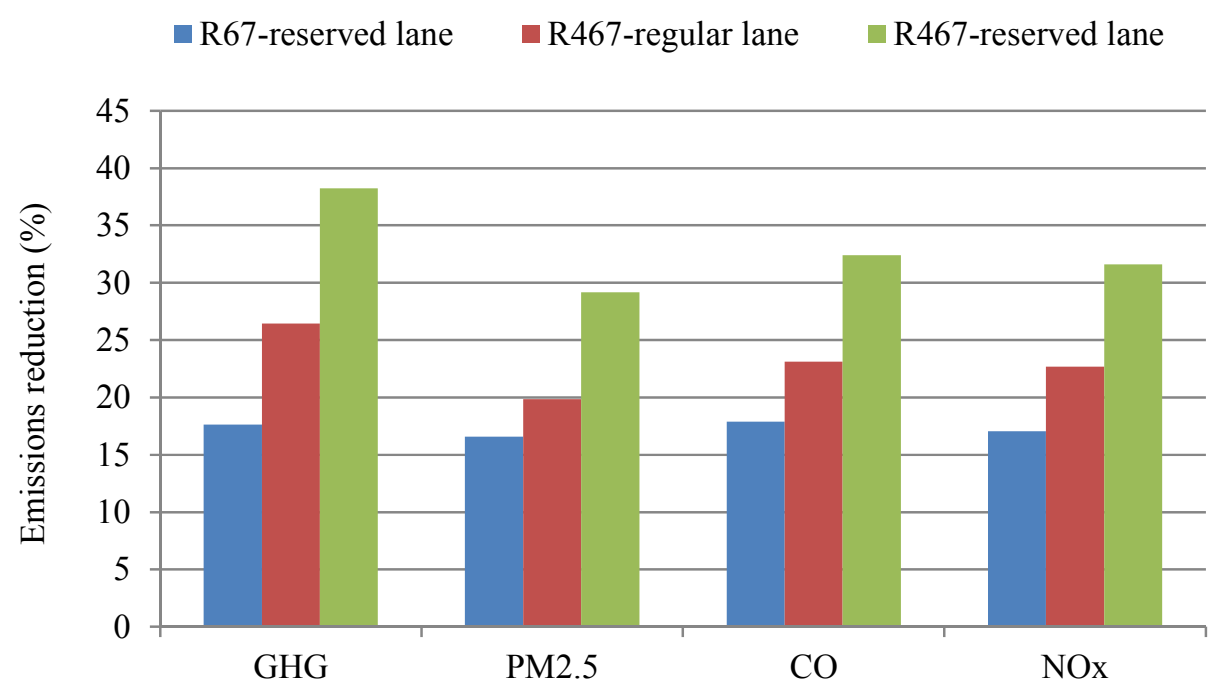

Fig. 7. Percent reductions in GHG and air pollutants under various service improvements (compared to the case of the regular bus without a reserved lane)

\subsection{Statistical analysis}

A linear regression of segment-level total emissions (including running and idling) and stop-level idling emissions was conducted for routes 67 and 467 against a set of potential explanatory variables described in Section 3.3. The segment level emissions regression was performed for GHG emissions (in grams) and $\mathrm{PM}_{2.5}$ emissions (in milligrams) and the regression results are summarized in Table 3 and Table 4; where information from 132 segments is used to estimate the model. Table 5 presents the results for GHG idling emissions.

Table 3 shows that the largest positive impact on emissions is associated with the introduction of Reserved Bus Lanes that can reduce GHG emissions by $441 \mathrm{~g}$ per mile of bus travel. The express bus service, R467, has the second largest negative coefficient decreasing GHG emissions by $431 \mathrm{~g} / \mathrm{mile}$. Regarding the control variables, Passenger Activity (PAX) has a positive sign indicating that as the number of passengers boarding and alighting increases, total emissions increase. This increase is mainly associated with longer idling time. But the square term of $P A X$ has a negative sign indicating that the relationship between total emissions and $P A X$ is not linear; after a certain number of passengers, total emissions start to decrease. This decrease is associated with two potential factors: (1) the relationship between dwell time and the number of boarding/alighting passengers is not linear, as the number of passengers increases, the time required for each passenger to board/alight decreases (El-Geneidy and Vijayakumar, 2011); (2) the average bus speed increases as drivers tend to drive faster when the bus has a higher number of passengers onboard (El-Geneidy \& Surprenant-Legault, 2010).

Finally, time of day and direction of travel were also observed to significantly affect bus emissions. If the bus runs southbound, total emissions are $101 \mathrm{~g} / \mathrm{mile}$ less than the northbound trips; this is due to the traffic conditions and geometric configuration of the corridor. It was also observed that trips made during the $P M$ peak period have emissions higher by $263 \mathrm{~g} / \mathrm{mile}$ compared to the AM peak period. Similar effects can be observed for $\mathrm{PM}_{2.5}$ as shown in Table 4.

Table 5 illustrates the effect of different variables on idling emissions at bus stops. Each Smart Card User increases GHG emissions by 7.5 g. Each Magnetic Card User and Cash User 
increases emissions by $9.2 \mathrm{~g}$ and $13.7 \mathrm{~g}$ respectively. These two fare payment processes take longer processing time compared to the smart card (Kittelson \& Associates, KFH Group, Parsons Brinckerhoff Quade \& Douglass, \& Hunter-Zaworsk, 2003). Each No Fare User increases emissions by $13.2 \mathrm{~g}$. Even though these users do not pay a fare (e.g. children or infants) they often take time to board the bus. The level of emissions generated for each alighting passenger depends on the door location. Alighting through the first door (door 1) generates almost 1.5 to 2 times higher emissions compared to alighting via the $2^{\text {nd }}$ and $3^{\text {rd }}$ doors. We also observe that crowding is associated with a reduction in idling emissions meaning that as the number of standing people near the door increases, emissions start to decrease because of faster alighting. $P A X$ Square was also found to be negative indicating that when the passenger activity is very high then the effect of each additional passenger on idling emissions starts to decrease. After controlling for the other variables, we observe that the express bus (R467) and Reserved Lane do not significantly affect idling emissions at bus stops.

Table 3 Regression results for GHG emissions (g/bus.mile)

\begin{tabular}{lccc}
\hline & Coefficient & Std. Error & $\mathrm{t}$ \\
\hline Constant & $2111.84 * * *$ & 143.420 & 14.723 \\
R467 & $-430.60^{* * *}$ & 60.711 & -7.093 \\
Reserved lane & $-441.14^{* * *}$ & 60.191 & -7.329 \\
PM Peak & $263.04 * * *$ & 58.461 & 4.499 \\
Southbound & $100.96^{*}$ & 61.003 & 1.655 \\
Total Passenger Activity (PAX) & $5.41 * *$ & 2.262 & 2.389 \\
PAX Square & $-0.02 *$ & 0.009 & -1.954 \\
\hline $\mathrm{R}^{2}=0.561$ & & & \\
\hline$* * *$ Significant at $99 \% * *$ Significant at $95 \% *$ Significant at $90 \%$ & & \\
\hline
\end{tabular}

Table 4 Regression results for PM2.5 emissions (mg/bus.mile)

\begin{tabular}{lrcc}
\hline & Coefficient & Std. Error & $\mathrm{t}$ \\
\hline Constant & $28.19^{* * *}$ & 1.049 & 26.871 \\
R467 & $-4.27^{* * *}$ & .444 & -9.626 \\
Reserved lane & $-4.44^{* * *}$ & .440 & -10.084 \\
PM & $4.04^{* * *}$ & .428 & 9.444 \\
Southbound & $1.25^{* * *}$ & .446 & 2.809 \\
Total Passenger Activity (PAX) & $.04^{* * *}$ & .017 & 2.271 \\
PAX Square & $-6.97^{*} 10^{-5}$ & .000 & -1.085 \\
\hline $\mathrm{R}^{2}=0.755$ & & & \\
\hline$* * *$ Significant at $99 \% * *$ Significant at $95 \% *$ Significant at $90 \%$ & & \\
\hline
\end{tabular}


Table 5 Regression results for GHG idling emissions (g) at bus stop

\begin{tabular}{lccc}
\hline & Coefficient & Std. Error & $\mathrm{t}$ \\
\hline Constant & $15.510^{* * *}$ & 1.748 & 8.873 \\
Smart Card User & $6.518^{* * *}$ & 0.185 & 35.315 \\
Magnetic Swipe Card User & $9.240^{* * *}$ & 0.963 & 9.591 \\
Cash User & $13.686^{* * *}$ & 1.662 & 8.234 \\
No Fare User & $13.169 * * *$ & 1.584 & 8.316 \\
Door1 Alight & $2.617^{* * *}$ & 0.462 & 5.664 \\
Door2 Alight & $1.740^{* * *}$ & 0.373 & 4.664 \\
Door3 Alight & $1.395^{* * *}$ & 0.366 & 3.815 \\
Bus Stop Level Crowding & $-.345^{*}$ & 0.186 & -1.854 \\
PAX Square & $-.015^{* * *}$ & 0.002 & -6.776 \\
Southbound & $2.603 *$ & 1.482 & 1.757 \\
PM Peak & 0.327 & 1.484 & 0.22 \\
R467 & -1.123 & 1.663 & -0.675 \\
Reserved lane & 0.941 & 1.468 & 0.641 \\
\hline $\mathrm{R}^{2}=0.779$ & $\mathrm{~N}=1,556$ stop level observations & \\
\hline$* * *$ Significant at 99\%** Significant at 95\%* Significant at 90\% & & \\
\hline
\end{tabular}

\section{CONCLUSION}

This study investigates the impacts of various service improvement strategies on transit bus emissions along the Saint Michel corridor in Montreal, Canada. To estimate emissions, second-by-second bus speeds as well as stop level passenger information were collected. GHG and air pollutant emissions were estimated at a segment level for total emissions (including running and idling) as well as at stop level for idling emissions. The resulting segment-level and passenger-level emissions were compared across different strategies. A regression analysis was conducted in order to quantify the effects of service improvements on segment level total and stop level idling emissions. We observe that the highest reduction in emissions comes from the implementation of reserved bus lanes and express bus service. Together; both strategies could reduce GHG emissions by $40 \%$ compared to the scenario with regular bus and no reserved lanes. We also observe that the smart card leads to lower idling emissions compared to magnetic swipe cards and cash. Also passengers should be encouraged not to alight through the first door.

It is important to note that along the corridor, reserved lanes are curb-side located in the rightmost lane. However, they are not continuous throughout the corridor but rather end $50 \mathrm{~m}$ upstream of each intersection thus allowing a passage to the right turning vehicles for their safe maneuvers. In Montreal, a 'no right turn on red' policy is always in effect for passenger cars and therefore buses have to idle behind passenger cars waiting to take a right turn. In this context, the introduction of queue jumper lanes near intersections is recommended since they would allow buses to bypass the waiting cars thus reducing congestion at intersections 


\section{ACKNOWLEDGEMENTS}

This research was supported by federal funding through the Natural Sciences and Engineering Research Council of Canada (NSERC).

\section{REFERENCES}

Alam, A. , \& Hatzopoulou, M. . (2013). A microscopic simulation of transit bus emissions under transit signal priority and alternative technology. Paper presented at the The 92nd Annual Meeting of the Transportation Research Board Meeting, Washington, DC, USA.

Diab, E., \& El-Geneidy, A. (2013). Variation in bus transit service: understanding the impacts of various improvement strategies on transit service reliability. Public Transport, 4(3), 209231. doi: 10.1007/s12469-013-0061-0

Dion, F., Rakha, H., \& Zhang, Y. (2004). Evaluation of potential transit signal priority benefits along a fixed-time signalized arterial. Journal of Transportation Engineering-ASCE, 130(3), 294-303.

El-Geneidy, A., \& Surprenant-Legault, J. (2010). Limited-stop bus service: An evaluation of an implementation strategy. Public Transport: Planning and Operation, 2(4), 291-306.

El-Geneidy, A., \& Vijayakumar, N. (2011). The effects of articulated buses on dwell and running times. Journal of Public Transportation, 14(3), 63-86.

Hemily, B., \& King, R. (2008). TCRP Synthesis 75: Uses of higher capacity buses in transit service. Washington, D.C.: Transportation Research Board.

Kimpel, T., Strathman, J., Bertini, R., Bender, P., \& Callas, S. (2005). Analysis of transit signal priority using archived TriMet bus dispatch system data. Transportation Research Record(1925), 156-166.

Kittelson \& Associates, KFH Group, Parsons Brinckerhoff Quade \& Douglass, \& HunterZaworsk, K. (2003). Transit capacity and quality of service manual. In n. Edition (Ed.). Washington D.C., USA.: TRB Transportation Research Board.

Li, Q., Xiaomeng, C., Cui, X., Tang, L., Li, Z. , \& Liu, C. (2010). A road segment based vehicle emission model for real-time traffic GHG estimation. Paper presented at the The Transportation Research Board 90th annual meeting, Washington, D.C.

Riga, A. (2012, July 2, 2012). 10-Minutes Max - a frequent-bus network ridership success but are articulated buses a mistake?, Montreal Gazette. Retrieved from http://blogs.montrealgazette.com/2012/07/02/10-minutes-max-a-frequent-bus-networkridership-success-but-are-articulated-buses-a-mistake/

Société de Transport de Montréal. (2011). The 467 Express, a taste of tomorrow's transit. Retrieved 11th July, 2011, from http://www.stm.info/english/info/a-467.htm

Surprenant-Legault, J., \& El-Geneidy, A. (2011). Introduction of a reserved bus lane: Impact on bus running time and on-time performance. Transportation Research Record(2218), 1018.

Tétreault, P., \& El-Geneidy, A. (2010). Estimating bus run times for new limited-stop service using archived AVL and APC data. Transportation Research Part A: Policy and Practice, 44(6), 390-402.

USEPA. (2010). MOVES2010 highway vehicle: Population and activity data. Assessment and Standards Division Office of Transportation and Air Quality U.S. Environmental Protection Agency. $\quad$ Retrieved 21st July, 2013 from http://www.epa.gov/otaq/models/moves/420r10026.pdf 